\title{
Erratum: Agbio groups join BIO
}

\section{Jeffrey L. Fox}

Nat. Biotechnol. 22, 1493 (2004)

Erratum: Nat. Biotechnol. 23, 117 (2005)

The erratum incorrectly stated that "CropLife International...sometimes receives funding from CBI." In fact, CropLife International provides funding to the Council for Biotechnology Information (CBI), not the other way around.

Erratum: Chasing biotech, state by state—winners and losers

\section{Ken Howard Wilan}

Nat. Biotechnol. 23, 175-179 (2005)

On page 178, paragraph 2, line 7, it was erroneously reported that “Rockefeller University (New York, NY, USA) still doesn't have a tech transfer office." The university has had a tech transfer office since 2000.

\section{Erratum: Clone on the range: what animal biotech brings to the table}

\section{Alan Dove}

Nat. Biotechnol. 23, 283-285 (2005)

On page 285, last column, paragraph 2, last line, the reduction in fecal phosphorus was reported as $30 \%$. It should have read $70 \%$.

Corrigendum: Problems in monitoring horizontal gene transfer in field trials of transgenic plants

Jack A. Heinemann \& Terje Traavik

Nat. Biotechnol. 22, 1105-1109 (2004)

On page 1108 , paragraph 1 , line 7 , reference 49 in the statement " $B$. thuringiensis has 'a significant history of mammalian pathogenicity' 46 and is thus not irrelevant to food safety or other environmental issues" was inappropriately cited (reference 46 states: "Bt does not have a significant history of mammalian pathogenecity".) The text should have read that " $B$. thuringiensis belongs to a closely related clade of bacteria, which includes Bacillus cereus and Bacillus anthracis, and which has a significant history of mammalian pathogenicity 1,2 and is thus not irrelevant to food safety or other environmental issues. Members of this group are so closely related that they may be considered members of the same species, often differing only by the presence or absence of certain plasmids ${ }^{3,4}$."

1. Helgason, E., Caugant, D.A., Olsen, I. \& Kolsto, A.-B. Genetic structure of population of Bacillus cereus and B. thuringiensis isolates associated with periodontitis and other human infections. J. Clin. Microbiol. 38, 1615-1622 (2000).

2. Økstad, O.A., Hegna, I., Lindbäck, T., Rishovd, A.-L. \& Kolstø, A.-B. Genome organization is not conserved between Bacillus cereus and Bacillus subtilis. Microbiol. 145, 621-631 (1999).

3. Helgason, E. et al. Bacillus anthracis, Bacillus cereus, and Bacillus thuringiensis-one species on the basis of genetic evidence. Appl. Environ. Microbiol. 66, 2627-2630 (2000).

4. Hoffmaster, A.R. et al. Identification of anthrax toxin genes in a Bacillus cereus associated with an illness resembling inhalation anthrax. Proc. Natl. Acad. Sci. USA 101, 8449-8454 (2004). 